\title{
Liberalism and Home Equity Bias
}

\author{
Evangelos Benos and Marek Jochec*
}

April 29, 2009

\begin{abstract}
Countries whose citizens have liberal ideals are less biased toward domestic equity. Data from 30 countries suggests that economic as well as social liberalism is associated with proportionally higher foreign equity holdings. A one standard deviation increase in the level of economic (social) liberalism relative to time-series and cross-sectional averages, is associated with a $5 \%(2 \%)$ relative decrease of home equity bias. These results hold after controlling for standard rational and behavioral explanations of the home equity bias as well as country and time fixed effects.
\end{abstract}

\section{Introduction}

According to modern asset pricing theory, investors should hold the world market portfolio. As French and Poterba (1990) put it, "Since fortunes of nations do not always move together, investors can diversify their portfolios by holding assets in different countries." Nevertheless, investors seem to ignore the diversification benefits of international equity investing and hold portfolios that are highly concentrated on domestic equity. This pattern is labeled "home equity bias" and has been documented by several studies [French and Poterba (1990), Cooper and Kaplanis (1994), etc.]

There has been a large amount of research trying to explain this anomaly with most efforts having been directed at discovering rational explanations. This line of research has so far yielded poor results. For instance, Cooper and Kaplanis (1994) show that direct costs of international transactions, such as taxes and capital restrictions, cannot explain the home equity bias in calibrated models, unless implausibly low coefficients of risk aversion are assumed. It has also been postulated that since investing in foreign equities usually requires an understanding of foreign accounting principles and legal environments, these information acquisition costs render foreign investments unattractive. There is indeed indirect evidence that these costs are both real and significant. Coval and Moskowitz (2001) find that mutual fund managers earn abnormal returns in nearby investments. This indicates that investors

${ }^{*}$ The authors are Ph.D students in Economics and Finance respectively at the University of Illinois at Urbana-Champaign. They can be reached at ebenos@uiuc.edu and mjochec2@uiuc.edu. We are grateful to Jacques Miniane for providing his data on capital controls and to George Deltas, Josh Pollet and Anne Villamil for helpful comments and suggestions. Evangelos Benos is also grateful to the Economics Department at the University of Illinois for providing financial support. All errors are ours. 
trade local securities at an information advantage. Jun-Koo Kan and Stulz (1997) find that foreign investors prefer Japanese stocks that are better known to them to other Japanese stocks with which they are less familiar and which have higher expected returns. Nevertheless, these information costs also appear to be small when compared to the potential benefits of international diversification [See Lewis (1999)].

The home equity bias is also difficult to rationalize as a means of hedging against various forms of risk. Baxter and Jermann (1997) show that human capital returns are highly correlated with domestic stock market returns but not with foreign stocks. Thus, the idea that perhaps excess domestic holdings are a hedge against non-traded wealth such as human capital, is rejected. If anything, according to Baxter and Jerman, investors should be shorting the domestic equity market to purchase foreign stock. Similarly, home equity holdings cannot be thought of as a hedge against domestic inflation since that would require a positive correlation between stock returns and inflation ${ }^{1}$. The idea that the diversification potential already exists in domestic equities, by investing across several industries or in firms with multinational operations, is also rejected in the data. Using a sample of European countries, Heston and Rouwenhorst (1994) show that industrial structure explains very little of the cross-sectional difference in country return volatility. Jacquillat and Solnik (1978) also show that the betas of firms with multinational operations are, with respect to their home markets, close to one and thus provide minimal diversification benefits.

Overall, the home equity bias still poses a significant challenge to the "rational agent" paradigm and therefore researchers have more recently turned their attention to potential behavioral explanations. Based on the experimental findings of Heath and Tversky (1991), it has been hypothesized that familiarity may at least partially explain the home equity bias. Heath and Tversky found that "people prefer betting on an equiprobable chance event when they consider themselves knowledgeable, but not otherwise". This suggests that people tend to make bets when they feel they are more familiar with the context in which this bet is being made. Empirical evidence confirms this finding. Grinblatt and Keloharju (2001) find that investors in Finland are more likely to buy, hold and sell stocks of firms that communicate in the investor's native tongue and whose chief executives have the same cultural background. On a different front, Morse and Shieve (2008) employ a set of questions from the World Values Survey to measure patriotism across countries and then show that in a set of 53 countries, their patriotism metric has incremental explanatory power over the home equity bias.

Our paper continues the trend of exploring whether behavioral and societal characteristics impact the magnitude of the home equity bias. In particular, we examine if the home equity bias may partly be influenced by a society's set of economic and social ideals. We are motivated to examine this possibility by the fact that individual choice is heavily influenced by the ideas and perceptions that are dominant in a society at any given time ${ }^{2}$.

Since a defining characteristic of an economic or social ideology is the degree of freedom afforded to individuals to act according to their preferences, we classify societies as more or less liberal in the economic and social sense. When it comes to economics, a liberal society is one that favors a smaller government, lower taxes, and thus more individual responsibility for peoples' well being. A less liberal society would rather see the government playing a

\footnotetext{
${ }^{1}$ The correlation between stock returns and inflation is actually negative. See Fama and Schwert (1977).

${ }^{2}$ See for example Louis et.al. (2005).
} 
larger role in guaranteeing a minimum standard of living through transfers that are made possible by higher taxes. It would also favor more government ownership of business. In the social sense, a liberal society is again one that favors individual freedoms regarding aspects of non-economic behavior. This practically boils down to less government regulation about what individuals should or should not do. As an example, a socially liberal society would be more tolerant toward homosexuality whereas a socially conservative society would be less tolerant.

Why then should liberalism have any impact on peoples' investment decisions? Regarding economic liberalism, our intuition is that perhaps investors will exploit more the benefits of international diversification if they have a stronger belief in the very economic ideology that makes these opportunities possible. On the other hand, it may be less apparent why a society's degree of social liberalism (or lack thereof) should have any impact on the home equity bias. Socially liberal societies are more keen to accept changes in social institutions which usually involves relaxing the regulatory constraints that have been imposed by the government. Examples abound and include: the legalization of prostitution, the separation of church and state, the abolishment of discriminatory rules against homosexuals, etc. Socially conservative societies are more reluctant toward such changes. We therefore think that the level of social liberalism is a proxy of the extent to which societies are willing (for better or worse) to embrace new ideas. This in turn means that perhaps they are also more willing to invest abroad, since the ability of individuals to invest in foreign stock markets is also relatively new. Overall, we hypothesize that societies, which in general embrace changes more easily, will be more keen to exploit the new set of opportunities afforded by the liberalization of capital markets.

To measure liberalism, we exploit as set of questions that were asked in the World Values Survey (WVS) and we classify societies as more or less liberal in the economic and social sense by the answers respondents give to these questions. We also construct control variables for other popular explanations, both rational and behavioral, of the home equity bias. These control variables are the same with the ones used in the Morse and Shieve (2008) study. Overall, we have a panel of 30 countries spanning a 25-year period.

We find that more liberal societies, in both the economic and social sense, are significantly less biased toward domestic equity. Our specification is robust to fixed country and time effects. The results imply that a one standard deviation increase in the level of economic liberalism relative to time-series and cross-sectional averages, is associated with a $5 \%$ relative decrease of home equity bias. As for social liberalism, a one standard deviation relative increase is associated with a $2 \%$ relative decrease of the home equity bias.

In the rest of the paper we describe the data and the variables, we present the main results and conclude.

\section{Data and Summary Statistics}

We use annual data from 30 countries and over varying time frames within the 1980-2005 period. The set of countries in our sample is dictated by the availability of data but almost all major economies and many developing ones are included. The number of observations used in each test varies as in each specification different explanatory variables are used. 


\subsection{Measuring the Home Equity Bias}

We measure the level of the home equity bias in a given country by the difference of the country's domestic holdings to those implied by a capital asset pricing model. A country's domestic holdings is the fraction of equity investments made domestically over total equity investments after accounting for foreign holdings domestically. More precisely, the year $\mathrm{t}$ domestic holdings are defined as:

$$
\text { Domestic Holdings }_{t}=1-\frac{\text { Foreign Assets }_{t}}{\text { Market Cap } \text { Horeign Assets }_{t}-{\text { Foreign } \text { Liabilities }_{t}}_{\text {Forein }}}
$$

where "Foreign Assets" is the amount invested by residents in foreign equities and "Foreign Liabilities" is the amount invested by foreigners in domestic equities in a given year. "Market Cap" is the country's market capitalization. Our home equity bias measure is therefore:

$$
H E B_{t}=\text { Domestic Holdings }_{t}-\frac{\text { Market Cap }_{t}}{\text { World Market Cap }_{t}}
$$

We obtain the data on foreign assets/liabilities from the IMF/IFS database and the market capitalization values from Global Financial Data. Table 1 shows time-averaged values of HEB for all the countries in our sample over three subperiods that make up the entire sample time. A clear pattern that emerges is that the home equity bias measure is decreasing over time for almost all countries. Furthermore, there is significant cross-sectional variation; for instance, European countries tend to be less home biased than other developed and developing countries.

\subsection{Measuring Economic and Social Liberalism}

To construct measures of economic and social liberalism we use the responses to specific questions in the World Values Survey (WVS) ${ }^{3}$. The WVS has been carried out by an international network of social scientists and has been administered in 78 countries, to a minimum of 1,000 individuals per country, over four time periods: 1980-1982, 1990-1992, 1995-1997 and 1999-2001. Unfortunately, the earlier survey waves missed some of the countries and this is the reason why our panel is unbalanced.

Since the idea of a limited role for the government in economic affairs lies at the core of the doctrine of economic liberalism, we exploit two relevant questions in the WVS to measure economic liberalism in different countries and over time. The first question asks respondents how strongly they agree with the statement that people should take responsibility to provide for themselves versus the government taking that responsibility. The second question asks how strongly they agree with increased private ownership of business versus increased government ownership of business. In both questions respondents are asked to give a score between 1 and 10 with 10 meaning that they fully agree with the first proposition in each question and 1 meaning that they fully agree with the second proposition. The country average score is then our measure of economic liberalism with higher scores being indicative of more liberal beliefs.

\footnotetext{
${ }^{3}$ www.worldvaluesurvey.org
} 
Table 2 Panel B shows the correlation of the country-and-time average scores of the two questions. The high correlation indicates that the two questions measure the same thing. Table 3 shows the average score of the two questions in each country and in each of the survey waves. Several interesting patterns emerge here. First, developed countries tend to be more liberal than developing ones. However, there also is significant variation among developed countries with the US being more liberal than Europe and Europe being more liberal than Japan and Korea. In fact Japan and Korea have almost as high scores as most other developing non-OECD countries. The second pattern is that over the nineties and for the countries in our sample, liberalism seems to have lost some ground to more conservative thinking.

To measure the level of social liberalism we see how people respond to questions about three social issues that are controversial in many countries. These are: homosexuality, abortion and divorce. The survey asks respondents if each of these are justifiable or not. As before, a score between 1 and 10 is given with 10 corresponding to "Always justifiable" and 1 to "Never justifiable". Thus higher values are associated with more liberal societies in the social sense.

Table 4 shows the correlation of the country-and-time average scores of the three questions. As before, the scores are highly correlated allowing us to use all three questions as proxies for social liberalism. Table 5 shows the average score of the three questions in each country and in each of the survey waves. As with with economic liberalism, developed countries are also more liberal in the social sense than developing ones. Europe is more liberal than the US which in turn is more liberal than the Latin American and the Asian countries of our sample with the exception of Japan. Furthermore, within Europe, Scandinavian countries appear to be more liberal than countries in the mainland and particularly those in the South. Our data doesn't show any significant trend over time.

\subsection{Control Variables}

In our empirical tests we control for a number of popular explanations of the home equity bias. Our first control variable, "CapC" is a proxy for the transaction barriers in foreign investment in each of the countries of our sample. This proxy is constructed using the IMF Annual Reports on Exchange Arrangements and Exchange Restrictions ${ }^{4}$. It is the average of several dummies and so it takes values between 0 and 1 . Higher values indicate more capital controls and higher transaction costs. Intuition suggests that capital controls should magnify the home equity bias; nevertheless, the related literature ${ }^{5}$ has found that these transaction costs fail to explain it in its full magnitude.

We also control for the potential information acquisition costs involved in foreign investments. It is natural to think that the costlier it is to obtain information about a foreign equity market the less prone domestic investors will be to invest in that market. Our information cost control variable is motivated from a number of studies that show smaller distances to be associated with lower information costs [e.g. Coval and Moskowitz (2001)]. Therefore, for each country in our sample we proxy for the information acquisition cost by the sum of the

\footnotetext{
${ }^{4}$ See Miniane (2004) for the details of how this variable is constructed

${ }^{5}$ e.g. Cooper and Kaplanis (1994)
} 
market capitalizations of the neighboring countries ("MarCapN"). The market capitalization values are in trillions of current US dollars.

The third control variable is the country's Sharpe ratio. This is intended to capture the quality of domestic investment opportunities and thus the magnitude of the diversification benefit. Since a higher Sharpe ratio is indicative of a better return-risk tradeoff, it should - ceteris paribus - be positively related to the home equity bias. We calculate the Sharpe ratio each year and for each country using monthly observations over the previous five years following Sharpe (1994). The country market return is usually that of a broad index and the risk free rate is either the country three-month Treasury Bill rate or the country threemonth Interbank Borrowing Rate. The market and risk-free rates are obtained from Global Financial Data.

A behavioral explanation of the home equity bias that is supported empirically in several studies [e.g. Grinblatt and Keloharju (2001)] is that investors prefer domestic stocks because they are more familiar with the investment environment at home. Familiarity seems to make a difference when individuals face a decision that involves risk. Following similar studies [e.g. Morse and Shieve] we use as a proxy for familiarity with foreign markets the percentage of foreign born residents in a given country. This is motivated by the study of Bhattacharya and Roznik who find that US investment in foreign countries is positively influenced by the number of US residents who were born in that country. The relevant variable is the "International Migration Stock", (IMS) available in the World Bank WDI database.

We finally control for the level of patriotism in each country. Morse and Shieve show that in a cross-section of 53 countries patriotism has incremental explanatory power over the level of the home equity bias. They construct their patriotism measure from the answers that respondents in different countries give to the question: "How proud are you to be [nationality inserted]?" The answers range from 1 to 4 with 1 corresponding to "not proud" and 4 to "very proud". This data is also from the World Values Survey. We use the exact same procedure to construct our patriotism control variable. Table 6 presents summary statistics for the control variables.

\section{Empirical Tests and Results}

\subsection{Bivariate Analysis}

We start our analysis by looking at bivariate relationships. Table 7 shows the simple correlations between the dependent and explanatory variables. Because the variables that are constructed from the WVS responses (SL, EL and pat) are only available during the survey waves, the correlation coefficients are calculated from samples of different sizes.

Both of the explanatory variables of interest (SL and EL) are significantly negatively correlated with the measure of home equity bias suggesting that a higher degree of liberalism, in both the economic and social sense, is unconditionally associated with lower levels of home equity bias. The correlation between these two variables is also high, indicating that socially liberal countries tend to also be economically liberal. From the set of controls, only the capital controls (CapC) and familiarity (IMS) proxies are significantly correlated with the home equity bias metric. These results are very similar to the ones obtained by Morse and 
Shieve (2008). Finally, it is interesting to note the significantly negative correlation between patriotism and social liberalism as well as the negative correlations of the capital controls proxy with each of the liberalism measures.

\subsection{Panel Regressions}

A feature of our data is that the explanatory variables of interest are only available for a maximum of four years for each country since they are constructed from the WVS which was conducted in four waves. This leaves us with a very few (less than 60) country-year observations for the empirical tests. To go around this problem we use for each countryyear that the observations are missing the most recent WVS value for that country. This approach gives rise to a panel structure which in turn allows us to control for country and time specific fixed effects. Being able to control for both types of fixed effects is important in this particular study. On one hand, countries are inherently different in many characteristics that potentially influence the home equity bias (e.g. location, wealth, legal environment, tradition, etc.). On the other hand, the level of home equity bias is also likely to be affected by world-wide time-specific factors such as technological advances that facilitate trading and the easy access to information. Controlling for these factors by country and time dummies is therefore important in avoiding an omitted variable bias.

We first regress our dependent variable (HEB) on the average of the three social liberalism and the two economic liberalism scores controlling for capital controls (CapC), information acquisition costs (MarCapN), the home market risk and return tradeoff (Sharpe), familiarity with foreign cultures (IMS), patriotism (Pat) as well as country and time fixed effects. Thus, our specification is:

$$
\begin{aligned}
H E B_{i t} & =b S L_{i t}+c E L_{i t}+d \operatorname{Cap}_{i t}+e \operatorname{MarCapN}_{i t}+\text { fSharpe }_{i t} \\
& +g I M S_{i t}+h P A T_{i t}+\sum_{j=1}^{N} I_{[j=i]} k_{j}+\sum_{s=1}^{T} I_{[s=t]} l_{s}+u_{i t}
\end{aligned}
$$

where $S L_{i, t}$ and $E L_{i, t}$ are the social and economic liberalism scores for country $i$ in year $t$ and $I_{[j=i]}, I_{[s=t]}$ are the country and year dummies respectively. Since we control for country and time fixed effects, we effectively have a differences in differences estimation. That is, we look at how variations from cross-sectional means of variations from time-series means in the independent variables affect the same kind of variations in the dependent variable. These results are presented in Table 8.

Our variables of interest (EL and SL) are highly significant both separately and combined, suggesting that as countries become relatively more socially and economically liberal they also become relatively less biased toward domestic equity. The economic liberalism scores are more significant both economically and statistically than the social liberalism ones perhaps because the way people think about the economy is more important in determining their investment behavior than is the way they think about social issues. The effect is also economically significant. The coefficients of the last specification imply that a one standard deviation increase in the social liberalism score is associated with a $2 \%$ drop in the home equity bias metric and a one standard deviation increase in the economic liberalism score is associated with a $5 \%$ drop in the home equity bias metric. 
Regarding the control variables, the results are also interesting. Capital controls do not seem to have any significant effect on the home equity bias. Although the point estimate of the coefficient has the expected sign, it is statistically insignificant. We interpret this as evidence that the capital controls are not necessarily binding; even if the countries in our sample imposed no controls on capital flows, investors would likely still prefer to invest in domestic stock.

The coefficient on MarCapN is significant but contrary to what we would expect it is positive. In our opinion, this variable simply does a poor job in capturing the potential information costs involved in foreign equity investment. Perhaps geographic proximity is not as important to international investing as it is to domestic investing. The reason why the coefficient is significant simply has to do with the fact that on average, countries with small market capitalizations have higher levels of home equity bias and they also border with countries whose market capitalization is large.

The coefficient of the country Sharpe ratio is positive and significant as expected. That is probably because investors in countries where the risk adjusted market returns are high have ceteris paribus less of an incentive to invest abroad.

As we mentioned earlier, IMS is the percentage of foreign-born residents in a country and proxies for familiarity. The significantly negative coefficient suggests that a higher degree of familiarity with foreign cultures causes domestic investors to hold more foreign assets. This is consistent with the findings of Bhattacharya and Groznik as well as the experimental evidence in Heath and Tversky (1991).

Finally, the coefficient on patriotism is negative and significant. This may not necessarily contradict the results of Morse and Shieve. Although they do account for country fixed effects by looking at how time differences in patriotism affect time differences in the home equity bias, they do not account for time specific effects; that is, they do not control for the possibility that there are factors associated with time and which are more or less common across countries that potentially affect both patriotism and the level of home equity bias. Our specification does that by including year dummies. The negative coefficient implies that the effect of patriotism beyond any time trends and after controlling for country-specific effects is negative. Of course, it is rather counterintuitive to think that because patriotism increases the home equity bias decreases. We suspect that what is really behind this relationship is a time varying country effect ${ }^{6}$ that is related to both peoples' patriotic feelings and their investing behavior. It is plausible to think for instance that patriotic sentiment is associated with investors' optimism and/or changes in disposable income which also affects their tendency to invest abroad. In this case, an increase in optimism (which would be associated to an increase in patriotism) would cause investors to buy more foreign stocks and drive the home equity bias down.

To highlight the importance of time specific effects, Panel B of Table 8 presents the coefficients of some of the time dummies ${ }^{7}$. Two things are worth noting here: First, the coefficients become progressively smaller as time goes by. Second, they are all highly significant. This suggests that the gradual decline of the home equity bias that is evident in the raw data is to some extent caused by time specific factors that are largely common among countries.

\footnotetext{
${ }^{6}$ Because it is a time varying effect, it is not captured by the country dummies in our main specification.

${ }^{7}$ The omitted time dummies exhibit similar behavior.
} 
In Table 9 we look how the scores of the various economic and social liberalism questions individually affect the home equity bias metric. Among the social liberalism questions, the one on abortion has the most significant effect on the home equity bias metric. This could be because abortion is perhaps the most controversial of the social issues that respondents were asked to give an opinion on and thus countries that scored high on this question may be the most socially liberal of all.

\subsection{Non-linearities}

In our next set of tests, we examine if any of the explanatory variables have a non-linear effect on the home equity bias metric. We suspect that such effects will exist because of the very nature of our regressors. For instance, we expect the effect of peoples' liberalism (or lack thereof) on their investment behavior to depend on the existence of domestic investment opportunities (as captured by the country Sharpe ratio). If the domestic investment opportunities are good, investors may choose to invest domestically regardless of how liberal they are; that is, liberalism may only play a role when investing domestically is not a good option. A simple linear model assumes that the effects of the regressors are additive and ignores such interactions. As a result, one could reach misleading conclusions.

Since we suspect that some of the variables could have a non-linear effect on the home equity bias metric, we estimate a specification where we interact the social and economic liberalism variables with selected regressors. We start by estimating the following specification $^{8}$ :

$$
\begin{aligned}
H E B_{i t} & =b_{1} S L_{i t}+b_{2} E L_{i t}+b_{3} \operatorname{CapC}_{i t}+b_{4} \operatorname{MarCapN}_{i t}+b_{5} \text { Sharpe }_{i t}+b_{6} I M S_{i t} \\
& +b_{7} P A T_{i t}+c_{1} S L_{i t} \text { CapC }_{i t}+c_{2} S L_{i t} \text { Sharpe }_{i t}+c_{3} S L_{i t} I M S_{i t}+d_{1} E L_{i t} \text { Cap }_{i t} \\
& +d_{2} E L_{i t} \text { Sharpe }_{i t}+d_{3} E L_{i t} I M S_{i t}+\sum_{j=1}^{N} I_{[j=i]} k_{j}+\sum_{s=1}^{T} I_{[s=t]} l_{s}+u_{i t}
\end{aligned}
$$

The coefficients and p-values of the interaction terms appear in Panel A of Table 10. The results suggest that only the familiarity proxy (IMS) exhibits an interaction effect with both liberalism variables. This means that the effect of liberalism is magnified in the presence of familiarity. Furthermore, economic liberalism (EL) appears to be interacting with capital controls (CapC) with the intuitive explanation being that economic liberalism matters only to the extent that investors are not prevented by capital restrictions from purchasing foreign stocks.

To gain a better understanding of the statistical significance of the various explanatory variables, we do a series of F-tests, since in a model with interaction terms the estimated coefficients may be jointly significant even if they are individually insignificant. We first test if a model that includes a given variable as a main effect or as a factor in an interaction term has more explanatory power than a model that does not include the variable at all. Thus, if for example we wish to test whether familiarity (IMS) adds explanatory power or not, our

\footnotetext{
${ }^{8}$ We do not interact the liberalism variables with "MarCapN" and "PAT" because of the opposite than expected coefficients of these variables.
} 
null hypothesis will be:

$$
H_{0}: b_{6}=c_{3}=d_{3}=0
$$

If this null is rejected, then the model that includes IMS as a stand alone variable and as an interaction term, has more explanatory power over the home equity bias metric than a model that does not include IMS at all. We also test whether the marginal effect of each of the explanatory variables that we interact is significant or not. From model (4) the marginal effect of (say) IMS on the home equity bias metric is:

$$
\frac{\partial H E B_{i t}}{\partial I M S_{i t}}=b_{6}+c_{3} S L_{i t}+d_{3} E L_{i t}
$$

Since the effect depends on the value of the liberalism variables due to the non-linearity of the specification, we test if the marginal effect is significant at the mean value of the liberalism scores. Thus, our second type of null hypothesis is:

$$
H_{0}: b_{6}+c_{3} \overline{S L}+d_{3} \overline{E L}=0
$$

where $\overline{S L}$ and $\overline{E L}$ are the pooled averages of the liberalism scores. The p-values of both of these F-tests for each of the variables as well as the point estimates of the marginal effects are shown in Panels B and C of Table 10. The point estimates have the anticipated signs and all null hypotheses are rejected at the $10 \%$ level while some are rejected at even lower levels of significance. The liberalism variables remain highly significant while now we can also reject the hypothesis that capital controls have no effect.

A concern with the estimation of model (4) however is that some p-values may be too large because of multicollinearity. This can happen if the same variables appear more than once in the model as factors of interaction terms. In order to address this issue and obtain a more parsimonious model, we next drop from the regression those interaction terms that are insignificant $(S L \times C a p C, S L \times$ Sharpe, $E L \times S h a r p e)$ and re-estimate the reduced model:

$$
\begin{aligned}
H E B_{i t} & =b_{1} S L_{i t}+b_{2} E L_{i t}+b_{3} \operatorname{Cap}_{i t}+b_{4} \text { MarCapN }_{i t}+b_{5} \text { Sharpe }_{i t}+b_{6} I M S_{i t} \\
& +b_{7} P A T_{i t}+c_{3} S L_{i t} I M S_{i t}+d_{1} E L_{i t} \operatorname{Cap}_{i t}+d_{3} E L_{i t} I M S_{i t} \\
& +\sum_{j=1}^{N} I_{[j=i]} k_{j}+\sum_{s=1}^{T} I_{[s=t]} l_{s}+u_{i t}
\end{aligned}
$$

We then repeat the tests (5) and (6) for the coefficients of the remaining terms. These results appear in Table 11. Indeed, the marginal effect of familiarity (IMS) and capital controls (CapC) is now statistically more significant. The coefficients and p-values of the marginal effects of the liberalism variables are similar as before and are skipped.

\subsection{Further Tests}

In the last section of the paper we do two more tests. First, we vary our dataset in an attempt to see whether the effect of liberalism persists when countries with outlier regressor values are excluded. For this, we re-estimate specification (3) excluding all Latin American 
countries. The reason we do this is that Latin American countries traditionally had much higher levels of capital controls than the rest of the countries in our sample. This is verified in our data. The country and time average value of the capital control variable (CapC) for Latin American countries is 0.82 , whereas the average for the rest of the sample is 0.46. If high capital controls make it impossible for Latin American investors to purchase foreign stocks, then the effect of the other variables in model (3) is distorted. The results of this test are in Table 12. The liberalism coefficients are similar in magnitude and economic significance to the ones derived from the full dataset. This supports our earlier conjecture that in the case of the home equity bias, capital controls may not be a binding constraint; that is, even if capital controls were low, the tendency of investors to purchase domestic stock would not be greatly affected.

The second test is to see whether government transfers have any effect on the home equity bias. In a country where the redistribution of wealth is substantial, there is presumably less need for individuals to save for the future ${ }^{9}$. This could in turn mean that the home equity bias in these countries is larger as individuals may not need (or may not be able) to invest abroad. We thus add as a regressor to specification (3) the variable "GovEx", the amount of government expenditures as a percentage of GDP ${ }^{10}$. For this test, we restrict our attention to the high-income OECD countries of our sample because we suspect that in these countries government transfers will generally be more effective ${ }^{11}$. That is, in a non-OECD (or generally poorer) country that (say) is plagued by corruption, a higher rate of government expenditure may not necessarily translate to a higher level of social benefits. The test results are in Table 13. Among the OECD countries of our sample there is significant variation in government spending as a proportion of GDP (see Panel A); however, the relevant coefficient is insignificant (Panel B). There are several reasons why this might be so. First, general government expenditure may be an inaccurate measure of social benefits as it includes such expenses as defense and infrastructure spending that do not directly affect the propensity of individuals to save. Alternatively, social benefits may just have a second order effect on the home equity bias, meaning that the main decision individuals make in the presence or absence of such benefits is whether to participate in the stock market at all and not whether to invest domestically or abroad.

\section{Summary and Conclusions}

The home equity bias is one of the big - yet to be fully understood - puzzles in financial economics. This is largely because the potential rational explanations that have been proposed so far cannot fully account for its magnitude. In an attempt to explain why investors forgo important diversification benefits associated with international investing, researchers have more recently been adding to their empirical specifications variables that proxy for behavioral factors such as familiarity and patriotism.

\footnotetext{
${ }^{9}$ In these countries individuals will likely also have less disposable income to save due to higher taxation.

${ }^{10}$ Absolute government expenditure and GDP data in the local currencies is obtained from the IMF-IFS database.

${ }^{11}$ The countries we exclude are: Argentina, Brazil, Chile, Colombia, India, Mexico, Philippines, Singapore, South Africa and Turkey.
} 
Following this trend, we examine in this paper if liberalism (or conservatism) has any incremental explanatory power over the level of the home equity bias. We make a distinction between social and economic liberalism not only because these are different notions per se, but mainly because we suspect that each one may separately affect peoples' investment behavior. We exploit the responses to selected questions in the World Values Survey to construct country metrics of social and economic liberalism. Using data from 30 countries, we then examine if these metrics help explain the home equity bias after controlling for the level of a country's degree of liberalization, the potential cost of information acquisition, the country risk-adjusted average stock market return, the familiarity of the country's residents with foreign cultures and their level of patriotism.

We find that liberal societies, in both the economic and social sense, are conditionally less biased toward domestic stock. The effect is economically significant: a one standard deviation increase in our social (economic) liberalism metric is associated with a $2 \%(5 \%)$ drop in the level of home equity bias. We interpret these results as evidence that peoples' investment decisions are influenced by their core beliefs about the economy and the society in which they live. It may come as no surprise that societies which have less trust to the open market and instead favor more government intervention are less likely to invest in foreign equities. It is however less apparent why social liberalism/conservatism should have any effect on individuals' investment behavior. We conjecture that social liberalism is a proxy for a society's willingness to accept changes in general and since in historical terms international investing is modernity, socially liberal societies are more likely to pioneer the transition to international investing. 


\section{References}

Baxter, Marianne and Urban Jermann, 1997, "The International Diversification Puzzle is worse than you think", American Economic Review 87:1, 170-80.

Bekaert Gert and Cambell Harvey, 2000, "Foreign Speculators and Emerging Equity Markets", Journal of Finance 45, 565-613.

Bhattacharya, Utpal and Peter Groznik, "Melting Pot or Salad Bowl? Some Evidence from US Investments Abroad", forthcoming, Journal of Financial Markets.

Cooper Ian and Evi Kaplanis, 1994, "Home Bias in Equity Portfolios, Inflation Hedging and International Capital Market Equilibrium", The Review of Financial Studies Vol. 7, No. $1,45-60$.

Coval Josh and Tobias Moskowitz, 2001, "Home Bias at Home: Local Equity Preference in Domestic Portfolios", Journal of Finance 54, 2045-2074.

Fama Eugene and G. Schwert, 1977, "Asset Returns and Iflation", Journal of Financial Economics 5, 115-46.

French Kenneth and James Poterba, 1991, "Investor Diversification and International Equity Markets", American Economic Review 81, 221-226.

Grinblatt, Mark and Matti Keloharju, 2001, "Distance, Language and Culture Bias: The Role of Investor Sophistication", Journal of Finance 56, 1053-1073.

Hardouvelis Gikas, Rafel La Porta and Thierry Wizman, 1994, "What Moves the Discount on Country Equity Funds?", in The Internationalization of Equity Markets. Jeffrey A. Frankel, ed. Chicago and London: U. Chicago Press, 345-97.

Heath, Chip and Amos Tversky, 1991, "Preference and Belief: Ambiguity and Competence in Choice Under Uncertainty", Journal of Risk and Uncertainty 4, 5-28.

Heston Steven and Geert Rouwenhorst, 1994, "Does Industrial Structure Explain the Benefits of International Diversification?", Journal of Financial Economics, 36, 3-27.

Huberman Gur, 2001, "Familiarity Breeds Investment", The Review of Financial Studies 14, 659-680.

Jacquillat Bertrand and Bruno Solnik, 1978, "Multinationals are Poor Tools for Diversification", Journal of Portfolio Management, 4:2, 8-12.

Kang, Jun-Koo and Rene Stulz, 1997, "Why is there Home Bias? An Analysis of Foreign Portfolio Equity Ownership in Japan", Journal of Financial Economics 46:1, 3-28. 
Lewis Karen, 1999, "Trying to Explain Home Bias in Equities and Consumption", Journal of Economic Literature 37, 571-608.

Louis Winnifred, Taylor Donald and Rebecca Douglas, 2005, "Normative Influence and Rational Conflict Decisions : Group Norms and Cost-benefit Analyses for Intergroup Behavior", Group Processes 6 Intergroup Relations, Vol. 8, Issue 4, 355-374.

Miniane Jacques, 2004, "A New Set of Measures on Capital Account Restrictions", IMF Staff papers Vol. 51, No. 2.

Morse Adair and Sophie Sieve, 2008, "Patriotism in your Portfolio", forthcoming, Journal of Financial Markets

Obstfeld Maurice and Kenneth Rogoff, 2000, "The six major puzzles in international macroeconomics: Is there a common cause?", NBER Macroeconomics Annual, 15.

Sharpe William, 1994, "The Sharpe Ratio", Journal of Portfolio Management, 21, 49-58. 
Table 1: Time series averages in percentage of the home equity bias measure (HEB) for the countries in our sample over three subperiods of the sample time. In case data is not available for all the years of a subperiod we simply average the available annual observations in the subperiod. Blank spaces indicate no available data for that subperiod.

\begin{tabular}{l|ccc}
\hline \hline Country & \multicolumn{3}{|c}{} \\
& \multicolumn{3}{c}{ Subperiods } \\
\hline & $\mathbf{1 9 8 1 - 1 9 9 0}$ & $\mathbf{1 9 9 1 - 2 0 0 0}$ & $\mathbf{2 0 0 1 - 2 0 0 5}$ \\
Argentina & - & 100 & 100 \\
Australia & 90 & 86 & 81 \\
Austria & 83 & 67 & 25 \\
Belgium & 71 & 60 & 54 \\
Brazil & - & - & 98 \\
Canada & 90 & 85 & 83 \\
Chile & - & 94 & 81 \\
Colombia & 100 & 99 & 100 \\
Denmark & - & 76 & 60 \\
Finland & 100 & 94 & 64 \\
France & 84 & 82 & 68 \\
Germany & 82 & 68 & 50 \\
Greece & - & 98 & 94 \\
India & - & 99 & 99 \\
Italy & 90 & 87 & 62 \\
Japan & - & 80 & 79 \\
Korea & 100 & 99 & 96 \\
Mexico & - & 100 & 100 \\
Netherlands & 70 & 60 & 33 \\
Norway & - & 58 & 52 \\
Philippines & - & - & 99 \\
Portugal & - & 84 & 65 \\
Singapore & - & - & 26 \\
South Africa & 98 & 94 & 86 \\
Spain & 98 & 94 & 83 \\
Sweden & 96 & 78 & 59 \\
Switzerland & 62 & 60 & 50 \\
Turkey & - & 100 & 100 \\
United Kingdom & 73 & 68 & 60 \\
United States & 60 & 51 & 44 \\
\hline & & & \\
Mean & & & \\
Std. Dev. & & & \\
\hline & & & \\
\hline
\end{tabular}


Table 2: The two questions from the World Values Survey that we use as a measure of economic liberalism are listed in Panel A. The correlation between the responses to the two questions is presented in Panel $\mathrm{B}$. To calculate the correlations we restrict ourselves to the countries and years for which all three questions were asked. *, ** and $* * *$ indicate significance at $10 \%, 5 \%$ and $1 \%$ respectively.

\section{Panel A: Economic Liberalism Questions}

Question 1: Private ownership of business should be increased vs.

Government ownership of business should be increased

Question 2: People should take more responsibility to provide for themselves vs. The government should take more responsibility to ensure that everyone is provided for

Obs.: $\quad 52$

Panel B: Correlation Matrix

Question 1 Question 2

Question 1

Question $2 \quad 0.70^{* * *} \quad 1$ 
Table 3: Average question score by country of the two economic liberalism questions: "People should take more responsibility to provide for themselves vs. the government should take more responsibility to ensure that everyone is provided for" and "Private ownership of business should be increased vs. government ownership of business should be increased". Each respondent gives a score between 1 and 10. 10 means that one completely agrees with the first statement in each question and 1 means that one completely agrees with the second statement. Thus, higher scores indicate that a country is more liberal in the economic sense. Missing values indicate that either the survey was not conducted in this country at the given time or that the particular questions were not asked.

\begin{tabular}{l|cccc}
\hline \hline & & \multicolumn{4}{c}{ Survey Waves } \\
Country & $\mathbf{1 9 8 0 - 1 9 8 2}$ & $\mathbf{1 9 9 0 - 1 9 9 2}$ & $\mathbf{1 9 9 5 - 1 9 9 7}$ & $\mathbf{1 9 9 9 - 2 0 0 1}$ \\
\hline & & & & \\
Argentina & - & 6.6 & 5.6 & 4.8 \\
Australia & - & - & 6.6 & - \\
Austria & - & 7.6 & - & 7.3 \\
Belgium & - & 6.6 & - & - \\
Brazil & - & 5.8 & 5.7 & - \\
Canada & - & 7.3 & - & 6.6 \\
Chile & - & 4.8 & 4.8 & 4.5 \\
Colombia & - & - & 4.7 & - \\
Denmark & - & 7.0 & - & - \\
Finland & - & 7.1 & 6.2 & 6.6 \\
France & - & 6.8 & - & 7.0 \\
Germany & - & 7.2 & 5.6 & 6.4 \\
Greece & - & - & - & - \\
India & - & 6.2 & 5.2 & 4.6 \\
Italy & - & 6.1 & - & 6.1 \\
Japan & - & 5.0 & 5.1 & 5.4 \\
Korea & - & 6.5 & 4.7 & 4.7 \\
Mexico & - & 6.1 & 5.6 & 5.3 \\
Netherlands & - & 6.5 & - & 6.5 \\
Norway & - & 6.6 & 6.1 & - \\
Philippines & - & - & 5.2 & 5.1 \\
Portugal & - & 6.4 & - & 6.3 \\
Singapore & - & - & - & 5.3 \\
South Africa & - & 6.8 & 5.6 & 5.5 \\
Spain & - & 5.5 & 5.1 & 4.7 \\
Sweden & - & 7.2 & 6.9 & - \\
Switzerland & - & - & 7.6 & - \\
Turkey & - & 5.0 & 5.6 & 5.3 \\
United Kingdom & - & 5.9 & - & 6.4 \\
United States & - & 7.7 & 7.5 & 7.1 \\
\hline Mean & - & 6.3 & 5.6 & 5.7 \\
Std. Dev. & - & 0.8 & 0.9 & 0.9 \\
\hline
\end{tabular}


Table 4: The three questions from the World Values Survey that we use as a measure of social liberalism are listed in Panel A. The correlations between the responses to the three questions are presented in Panel B. To calculate the correlations we restrict ourselves to the countries and years for which all three questions were asked. *, ** and $* * *$ indicate significance at $10 \%, 5 \%$ and $1 \%$ respectively.

\section{Panel A: Social Liberalism Questions}

Question 1: Is homosexuality justifiable?

Question 2: Is abortion justifiable?

Question 3: Is divorce justifiable?

Obs.: $\quad 68$

\section{Panel B: Correlation Matrix}

\section{Question 1 Question 2 Question 3}

\begin{tabular}{cccc} 
Question 1 & 1 & & \\
Question 2 & $0.72^{* * *}$ & 1 & \\
Question 3 & $0.81^{* * *}$ & $0.87^{* * *}$ & 1 \\
\hline
\end{tabular}


Table 5: Average question score by country of the three social liberalism questions: "Is homosexuality justifiable?", "Is abortion justifiable?" and "Is divorce justifiable?". Each respondent gives a score between 1 and 10. 1 corresponds to "Never justifiable" and 10 to "Always justifiable". Thus, higher scores indicate that a country is more liberal in the social sense. Missing values indicate that either the survey was not conducted in this country at the given time or that the particular questions were not asked.

\begin{tabular}{|c|c|c|c|c|}
\hline Country & 1980-1982 & $\begin{array}{l}\text { Survey } \\
1990-1992\end{array}$ & $\begin{array}{l}\text { Waves } \\
\text { 1995-1997 }\end{array}$ & 1999-2001 \\
\hline Argentina & 3.4 & 4.0 & 4.5 & 4.1 \\
\hline Australia & 4.4 & - & 5.1 & - \\
\hline Austria & - & 3.9 & - & 5.2 \\
\hline Belgium & 3.5 & 4.3 & - & 5.1 \\
\hline Brazil & - & 3.2 & 3.4 & - \\
\hline Canada & 3.9 & 4.9 & - & 5.3 \\
\hline Chile & - & 2.4 & 3.3 & 3.9 \\
\hline Colombia & - & - & 2.7 & - \\
\hline Denmark & 6.4 & 5.3 & - & 6.9 \\
\hline Finland & - & 6.0 & 5.4 & 5.8 \\
\hline France & 4.7 & 4.9 & - & 5.7 \\
\hline Germany & 4.4 & 4.7 & 6.3 & 5.4 \\
\hline Greece & - & - & - & 5.4 \\
\hline India & - & 2.4 & 2.4 & 3.4 \\
\hline Italy & 4.2 & 4.6 & - & 4.7 \\
\hline Japan & 3.6 & 3.7 & 4.5 & 5.2 \\
\hline Korea & 3.4 & 3.4 & 3.2 & 3.6 \\
\hline Mexico & - & 3.8 & 3.3 & 3.7 \\
\hline Netherlands & 5.1 & 6.3 & - & 6.7 \\
\hline Norway & 4.5 & 4.8 & 5.7 & - \\
\hline Philippines & - & - & 3.1 & 3.3 \\
\hline Portugal & - & 3.7 & - & 4.2 \\
\hline Singapore & - & - & - & 2.8 \\
\hline South Africa & - & 3.0 & 2.9 & 3.2 \\
\hline Spain & 3.5 & 4.7 & 5.3 & 5.5 \\
\hline Sweden & 5.3 & 5.4 & 7.3 & 7.7 \\
\hline Switzerland & - & 4.1 & 5.9 & - \\
\hline Turkey & - & 3.6 & - & - \\
\hline United Kingdom & 4.3 & 4.3 & 5.7 & 5.1 \\
\hline United States & 3.5 & 4.2 & 4.4 & 4.7 \\
\hline Mean & 4.3 & 4.2 & 4.4 & 4.7 \\
\hline Std.Dev. & 0.8 & 1.0 & 1.3 & 1.3 \\
\hline
\end{tabular}


Table 6: Summary statistics of the control variables. "CapC" is a measure of the capital controls in a given country and is taken from Miniane (2004). "MarCapN" is the sum of capitalizations of neighboring countries in current trillion dollars. "Sharpe" is a country Sharpe ratio. "IMS" is the percentage of foreign-born residents in a given country. "Pat" is a patriotism measure constructed from peoples' responses to the question: "How proud are you to be [insert nationality]"? Respondents give a score between 1 and 4 with 1 corresponding to "Not proud at all" and 4 to "Very proud".

\begin{tabular}{l|cccc}
\hline \hline Control Variables & Mean & St.Dev. & Minimum & Maximum \\
\hline & & & & \\
CapC & 0.52 & 0.31 & 0.00 & 1.00 \\
MarCapN & 1.43 & 2.50 & 0.00 & 15.42 \\
Sharpe & 0.32 & 0.11 & -0.08 & 0.61 \\
IMS & 8.00 & 8.00 & 0.00 & 42.00 \\
Pat & 3.35 & 0.29 & 2.60 & 3.82 \\
\hline
\end{tabular}

Table 7: Simple correlations of the dependent and all independent variables. The sample size varies between some correlations because of limited availability of some of the variables. "CapC" is a measure of the capital controls in a given country and is taken from Miniane (2004). "MarCapN" is the sum of capitalizations of neighboring countries in current trillion dollars. "Sharpe" is a country Sharpe ratio. "IMS" is the percentage of foreign-born residents in a given country. "Pat" is a patriotism measure constructed from peoples' responses to the question: "How proud are you to be [insert nationality]"? Respondents give a score between 1 and 4 with 1 corresponding to "Not proud at all" and 4 to "Very proud". *, ** and *** indicate significance at 10\%, $5 \%$ and $1 \%$ respectively.

\begin{tabular}{l|llllllll}
\hline \hline & & & & & & \\
Correlations & HEB & SL & EL & CapC & MarCapN & Sharpe & IMS & Pat \\
\hline \multirow{2}{*}{ HEB } & 1.00 & - & - & - & - & - & - & - \\
SL & $-0.29^{* *}$ & 1.00 & - & - & - & - & - & - \\
EL & $-0.42^{* * *}$ & $0.46^{* * *}$ & 1.00 & - & - & - & - & - \\
CapC & $0.54^{* * *}$ & $-0.65^{* * *}$ & $-0.41^{* * *}$ & 1.00 & - & - & - & - \\
MarCapN & -0.06 & 0.11 & 0.03 & $-0.13^{* * *}$ & 1.00 & - & - & - \\
Sharpe & 0.00 & $0.45^{* * *}$ & $0.30^{* *}$ & 0.00 & $0.09^{* *}$ & 1.00 & - & - \\
IMS & $-0.54^{* * *}$ & 0.20 & $0.41^{* * *}$ & $-0.35^{* * *}$ & $0.10^{* *}$ & 0.04 & 1.00 & - \\
Pat & 0.18 & $-0.43^{* * *}$ & -0.14 & 0.13 & 0.02 & -0.03 & -0.06 & 1.00 \\
\hline
\end{tabular}


Table 8: Panel A: Country and time fixed effects specification. The coefficients of the country dummies are omitted. "HEB" is our home equity bias metric and is defined in the text, equation (2). "SL" is the average score for each country and in a given year of the two questions in Table 4, Panel A. "EL" is the average score for each country and in a given year of the three questions in Table 2, Panel A. "CapC" is a measure of the capital controls in a given country and is taken from Miniane (2004). "MarCapN" is the sum of capitalizations of neighboring countries in current trillion dollars. "Sharpe" is a country Sharpe ratio. "IMS" is the percentage of foreign-born residents in a given country. "Pat" is a patriotism measure constructed from peoples' responses to the question: "How proud are you to be [insert nationality]"? Respondents give a score between 1 and 4 with 1 corresponding to "Not proud at all" and 4 to "Very proud". Panel B: The coefficients and p-values of selected time dummies.

\begin{tabular}{c|ccccccc}
\hline \hline Panel A & SL & EL & CapC & MarCapN & Sharpe & IMS & Pat \\
\hline Coefficients & $\mathbf{- 1 . 9 1}$ & - & 2.58 & 0.53 & 17.43 & -1.05 & -21.32 \\
p-values & $\mathbf{0 . 0 2}$ & - & 0.30 & 0.04 & 0.00 & 0.00 & 0.00 \\
\hline Coefficients & - & $\mathbf{- 4 . 4 0}$ & 1.61 & 1.22 & 15.90 & -1.71 & -14.72 \\
p-values & - & $\mathbf{0 . 0 0}$ & 0.64 & 0.00 & 0.00 & 0.00 & 0.00 \\
\hline Coefficients & $\mathbf{- 2 . 1 6}$ & $\mathbf{- 4 . 4 5}$ & 2.00 & 1.23 & 17.00 & -1.54 & -14.50 \\
p-values & $\mathbf{0 . 0 3}$ & $\mathbf{0 . 0 0}$ & 0.56 & 0.00 & 0.00 & 0.00 & 0.00 \\
\hline
\end{tabular}

\begin{tabular}{c|cccccccc}
\hline \hline Panel B & 2004 & 2002 & 2000 & 1998 & 1996 & 1994 & 1992 & 1990 \\
\hline Coefficients & 4.68 & 5.57 & 5.40 & 11.47 & 16.48 & 21.48 & 21.63 & 21.43 \\
p-values & 0.00 & 0.00 & 0.00 & 0.00 & 0.00 & 0.00 & 0.00 & 0.00 \\
\hline
\end{tabular}


Table 9: Country and time fixed effects specification. The coefficients of the country and time dummies are omitted. "HEB" is our home equity bias metric and is defined in the text, equation (2). In Panel A it is regressed on "SL1", "SL2" and "SL3", the country-average scores of each the three social liberalism questions shown in Table 2, Panel A. In Panel B, "HEB" is regressed on each of the economic liberalism questions shown in Table 4, Panel A. "CapC" is a measure of the capital controls in a given country and is taken from Miniane (2004). "MarCapN" is the sum of capitalizations of neighboring countries in current trillion dollars. "Sharpe" is a country Sharpe ratio. "IMS" is the percentage of foreign-born residents in a given country. "Pat" is a patriotism measure constructed from peoples' responses to the question: "How proud are you to be [insert nationality]?". Respondents give a score between 1 and 4 with 1 corresponding to "Not proud at all" and 4 to "Very proud".

\begin{tabular}{c|cccccccc}
\hline \hline Panel A & SL1 & SL2 & SL3 & CapC & MarCapN & Sharpe & IMS & Pat \\
\hline Coefficients & $\mathbf{- 1 . 2 1}$ & - & - & 2.39 & 0.51 & 17.13 & -1.09 & -21.13 \\
p-values & $\mathbf{0 . 0 9}$ & - & - & 0.35 & 0.05 & 0.00 & 0.00 & 0.00 \\
\hline Coefficients & - & $\mathbf{- 1 . 6 7}$ & - & 4.16 & 0.49 & 17.96 & -1.06 & -20.80 \\
p-values & - & $\mathbf{0 . 0 2}$ & - & 0.11 & 0.06 & 0.00 & 0.00 & 0.00 \\
\hline Coefficients & - & - & $\mathbf{- 1 . 6 2}$ & 3.06 & 0.54 & 17.05 & -1.16 & -21.79 \\
p-values & - & - & $\mathbf{0 . 0 5}$ & 0.22 & 0.03 & 0.00 & 0.00 & 0.00 \\
\hline
\end{tabular}

\begin{tabular}{c|ccccccc}
\hline \hline Panel B & EL1 & EL2 & CapC & MarCapN & Sharpe & IMS & Pat \\
\hline Coefficients & $\mathbf{- 4 . 9 0}$ & - & 3.73 & 1.09 & 15.02 & -1.77 & -18.07 \\
p-values & $\mathbf{0 . 0 0}$ & - & 0.31 & 0.00 & 0.00 & 0.00 & 0.00 \\
\hline Coefficients & - & $\mathbf{- 2 . 4 7}$ & 2.42 & 1.20 & 16.74 & -1.74 & -12.83 \\
p-values & - & $\mathbf{0 . 0 0}$ & 0.48 & 0.00 & 0.00 & 0.00 & 0.00 \\
\hline
\end{tabular}


Table 10: Specification with interaction terms and country and time fixed effects. The coefficients of the country and time dummies are omitted. In Panel A we report point estimates and p-values of the interaction terms of model (4). In Panels B and C we report point estimates of the regressor marginal effects and p-values of the F-tests of the hypotheses (5) and (6). The dependent variable (HEB) is our home equity bias metric and is defined in the text, equation (2). "SL" is the average score for each country and in a given year of the two questions in Table 4, Panel A. "EL" is the average score for each country and in a given year of the three questions in Table 2, Panel A. "CapC" is a measure of the capital controls in a given country and is taken from Miniane (2004). "Sharpe" is a country Sharpe ratio. "IMS" is the percentage of foreign-born residents in a given country.

\begin{tabular}{c|cccccc}
\hline \hline Panel A & $S L \times C a p C$ & $S L \times$ Sharpe & $S L \times I M S$ & $E L \times C a p C$ & $E L \times$ Sharpe & $E L \times I M S$ \\
\hline \multirow{2}{*}{ Coefficients } & 2.21 & 2.14 & -0.57 & -6.49 & -0.58 & -1.43 \\
p-values & 0.54 & 0.50 & 0.01 & 0.05 & 0.89 & 0.00 \\
\hline
\end{tabular}

\begin{tabular}{c|ccc}
\hline \hline Panel B & CapC & Sharpe & IMS \\
\hline $\mathbf{H}_{\mathbf{0}}:$ & $b_{3}=c_{1}=d_{1}=0$ & $b_{5}=c_{2}=d_{2}=0$ & $b_{6}=c_{3}=d_{3}=0$ \\
p-values & 0.10 & 0.01 & 0.00 \\
\hline $\mathbf{H}_{\mathbf{0}}:$ & $b_{3}+c_{1} \overline{S L}+d_{1} \overline{E L}=0$ & $b_{5}+c_{2} \overline{S L}+d_{2} \overline{E L}=0$ & $b_{6}+c_{3} \overline{S L}+d_{3} \overline{E L}=0$ \\
P. Est. & 19.0 & 16.6 & -0.73 \\
p-values & 0.02 & 0.10 & 0.10 \\
\hline
\end{tabular}

\begin{tabular}{c|cc}
\hline \hline Panel C & SL & EL \\
\hline $\mathbf{H}_{\mathbf{0}}:$ & $b_{1}=c_{1}=c_{2}=c_{3}=0$ & $b_{2}=d_{1}=d_{2}=d_{3}=0$ \\
p-values & 0.00 & 0.00 \\
\hline $\mathbf{H}_{\mathbf{0}}:$ & $b_{1}+c_{1} \overline{C a p C}+c_{2} \overline{\text { Sharpe }}+c_{3} \overline{I M S}=0$ & $b_{2}+d_{1} \overline{C a p C}+d_{2} \overline{\text { Sharpe }}+d_{3} \overline{I M S}=0$ \\
P. Est. & -2.52 & -7.50 \\
p-values & 0.00 & 0.00 \\
\hline
\end{tabular}


Table 11: Specification with interaction terms and country and time fixed effects. The coefficients of the country and time dummies are omitted. In Panel A we report point estimates and p-values of the interaction terms of model (7). In Panel B we report point estimates of the regressor marginal effects and p-values of the F-tests of the "reduced" hypotheses (5) and (6). The dependent variable (HEB) is our home equity bias metric and is defined in the text, equation (2). "SL" is the average score for each country and in a given year of the two questions in Table 4, Panel A. "EL" is the average score for each country and in a given year of the three questions in Table 2, Panel A. "CapC" is a measure of the capital controls in a given country and is taken from Miniane (2004). "Sharpe" is a country Sharpe ratio. "IMS" is the percentage of foreign-born residents in a given country.

\begin{tabular}{c|ccc}
\hline \hline Panel A & $E L \times C a p C$ & $S L \times I M S$ & $E L \times I M S$ \\
\hline Coefficients & -6.21 & -0.62 & -1.44 \\
p-values & 0.05 & 0.00 & 0.00 \\
\hline
\end{tabular}

\begin{tabular}{c|cc}
\hline \hline Panel B & CapC & IMS \\
\hline $\mathbf{H}_{\mathbf{0}}:$ & $b_{3}=d_{1}=0$ & $b_{6}=c_{3}=d_{3}=0$ \\
p-values & 0.06 & 0.00 \\
\hline $\mathbf{H}_{\mathbf{0}}:$ & $b_{3}+d_{1} \overline{E L}=0$ & $b_{6}+c_{3} \overline{S L}+d_{3} \overline{E L}=0$ \\
P. Est. & 16 & -0.72 \\
p-values & 0.02 & 0.04 \\
\hline
\end{tabular}


Table 12: Country and time fixed effects specification excluding all Latin American countries. The coefficients of the country and time dummies are omitted. "HEB" is our home equity bias metric and is defined in the text, equation (2). "SL" is the average score for each country and in a given year of the two questions in Table 4, Panel A. "EL" is the average score for each country and in a given year of the three questions in Table 2, Panel A. "CapC" is a measure of the capital controls in a given country and is taken from Miniane (2004). "MarCapN" is the sum of capitalizations of neighboring countries in current trillion dollars. "Sharpe" is a country Sharpe ratio. "IMS" is the percentage of foreign-born residents in a given country. "Pat" is a patriotism measure constructed from peoples' responses to the question: "How proud are you to be [insert nationality]"?. Respondents give a score between 1 and 4 with 1 corresponding to "Not proud at all" and 4 to "Very proud".

\begin{tabular}{c|ccccccc}
\hline \hline $\begin{array}{c}\text { Latin America } \\
\text { Excluded }\end{array}$ & SL & EL & CapC & MarCapN & Sharpe & IMS & Pat \\
\hline Coefficients & $\mathbf{- 1 . 9 5}$ & - & 2.00 & 0.44 & 17.59 & -0.99 & -22.57 \\
p-values & $\mathbf{0 . 0 2}$ & - & 0.45 & 0.11 & 0.00 & 0.00 & 0.00 \\
\hline Coefficients & - & $\mathbf{- 4 . 3 0}$ & 0.90 & 1.17 & 16.57 & -1.65 & -15.54 \\
p-values & - & $\mathbf{0 . 0 0}$ & 0.81 & 0.00 & 0.00 & 0.00 & 0.00 \\
\hline Coefficients & $\mathbf{- 2 . 1 9}$ & $\mathbf{- 4 . 3 6}$ & 1.36 & 1.18 & 17.71 & -1.48 & -15.35 \\
p-values & $\mathbf{0 . 0 3}$ & $\mathbf{0 . 0 0}$ & 0.72 & 0.00 & 0.00 & 0.00 & 0.00 \\
\hline
\end{tabular}


Table 13: Panel A: Summary statistics for the "GovEx" variable for all OECD countries in our sample. "GovEx" is government consumption as a percentage (\%) of GDP. Panel B: Country and time fixed effects specification for the OECD countries in our sample. The coefficients of the country and time dummies are omitted. "HEB" is our home equity bias metric and is defined in the text, equation (2). "SL" is the average score for each country and in a given year of the two questions in Table 4, Panel A. "EL" is the average score for each country and in a given year of the three questions in Table 2, Panel A. "CapC" is a measure of the capital controls in a given country and is taken from Miniane (2004). "MarCapN" is the sum of capitalizations of neighboring countries in current trillion dollars. "Sharpe" is a country Sharpe ratio. "IMS" is the percentage of foreign-born residents in a given country. "Pat" is a patriotism measure constructed from peoples' responses to the question: "How proud are you to be [insert nationality]"? Respondents give a score between 1 and 4 with 1 corresponding to "Not proud at all" and 4 to "Very proud".

\begin{tabular}{l|cccc}
\hline \hline Panel A & Mean & St.Dev. & Minimum & Maximum \\
\hline GovEx & 18.9 & 4.6 & 7.6 & 30 \\
\hline
\end{tabular}

\begin{tabular}{c|cccccccc}
\hline \hline & & & & & & & & \\
Panel B & SL & EL & GovEx & CapC & MarCapN & Sharpe & IMS & Pat \\
\hline Coefficients & $\mathbf{- 2 . 5 4}$ & $\mathbf{- 4 . 4 3}$ & 0.48 & 1.73 & 1.40 & 18.13 & -1.38 & -13.62 \\
p-values & $\mathbf{0 . 0 2}$ & $\mathbf{0 . 0 0}$ & 0.30 & 0.66 & 0.00 & 0.00 & 0.00 & 0.00 \\
\hline
\end{tabular}

